\title{
Three arteries in coronary surgery: The trifecta to improving survival?
}

\author{
Derrick Y. Tam, MD, and Stephen E. Fremes, MD, MSc
}

\author{
From the Division of Cardiac Surgery, Schulich Heart Centre, Department of Surgery, Sunnybrook Health Sci- \\ ences Centre, University of Toronto, Toronto, Ontario, Canada. \\ Disclosures: Authors have nothing to disclose with regard to commercial support. \\ Received for publication Oct 28, 2017; accepted for publication Oct 30, 2017; available ahead of print Jan 2, 2018 \\ Address for reprints: Stephen E. Fremes, MD, MSc, FRCSC, FACP, FACC, Dr Bernard S. Goldman Chair in Car- \\ diovascular Surgery, Schulich Heart Centre, Sunnybrook Health Sciences Centre, 2075 Bayview Ave, Room \\ H4 05, Toronto, Ontario M4N 3M5, Canada (E-mail: Stephen.fremes@sunnybrook.ca). \\ J Thorac Cardiovasc Surg 2018;155:853-4 \\ $0022-5223 / \$ 36.00$ \\ Copyright (c) 2017 by The American Association for Thoracic Surgery \\ https://doi.org/10.1016/j.jtcvs.2017.10.124
}

In this issue of the Journal, Luthra and colleagues ${ }^{1}$ tackle a relevant question in coronary surgery: Does a third arterial conduit to the right coronary circulation, in addition to 2 arterial conduits to the left circulation, improve survival? Since the seminal work by Loop and colleagues first showed the superior patency of the internal thoracic artery (ITA) when grafted to the left anterior descending coronary artery, there has been much enthusiasm to expand the use of arterial conduits in patients undergoing coronary artery bypass grafting. ${ }^{2,3}$

The right coronary circulation differs from the left coronary circulation in that arterial grafting to the right coronary is permissive only in the presence of a high grade stenosis, greater than $90 \%$ for radial artery (RA) grafts and greater than $80 \%$ for ITA. In the study of Luthra and colleagues, ${ }^{1}$ propensity scoring was used to match 132 pairs of patients on several important baseline characteristics that are predictive of mortality. Early 30-day mortality was very low and not different between the groups before or after propensity matching. Intermediate survival at 7 years was not statistically different, although it was numerically lower in the saphenous vein graft group in both the unmatched $(69.0 \%$ vs $83.5 \% ; P=.84)$ and matched comparisons $(69.2 \%$ vs $88.8 \% ; P=.29)$.

The ideal revascularization target for the second ITA after the left anterior descending coronary artery remains uncertain. Tatoulis and colleagues ${ }^{4}$ demonstrated that when the right ITA was grafted to the right coronary or posterior descending artery, angiographic patency at 10 years was lower than with the right ITA grafted to the circumflex territory. Conversely, findings from a propensity scoreadjusted analysis of more than 3000 patients from the Cleveland Clinic show that 10 -year survival in patients undergoing bilateral ITA grafting was comparable in those who received a second ITA to the circumflex coronary artery and those who received one to the right coronary artery. ${ }^{5}$ Similarly, Kurlansky and colleagues ${ }^{6}$ showed similar results in 2215 patients undergoing bilateral ITA

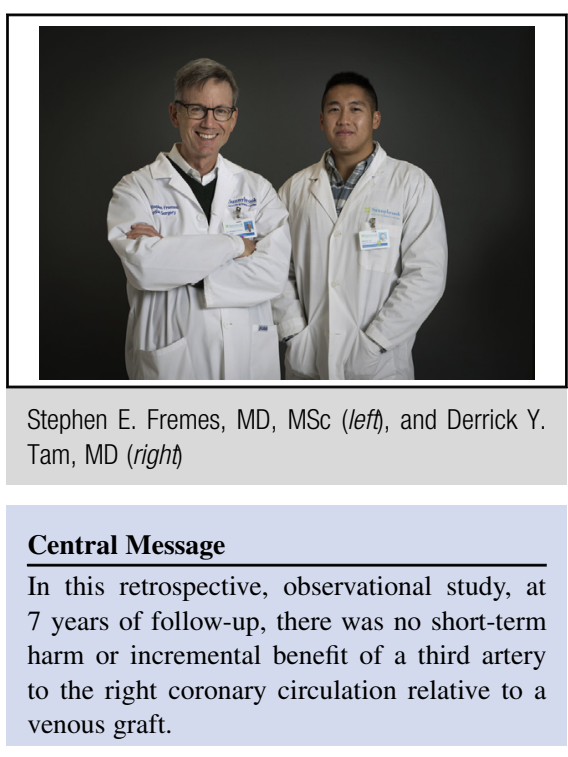

See Article page 855 .

grafting with the ITA anastomosed to the left coronary system in 1479 patients and to the right in 736 patients. After propensity score matching to create 730 pairs, there was no difference in late survival at 16 years of follow-up. Other conduits for total arterial revascularization (TAR) include the right gastroepiploic artery and the RA. The use of the right gastroepiploic artery to the right coronary system was studied by Glineur and colleagues ${ }^{7}$; graft patency was decreased in those with less severe lesions. Total arterial revascularization with bilateral RAs coupled with the left ITA has been described as well; however, patency was lower in RAs grafted to the right coronary artery than in those grafted to the left system. ${ }^{8}$ In the center of Luthra and colleagues, ${ }^{1}$ the RA seems to be the most common second and third arterial conduit.

The strengths of this study include the linkage of a clinically rich and accurate single-institution database with a mortality database to ascertain long-term survival. The use of single-center data ensured uniformity in the selection of conduits for the right-sided circulation; specifically, RAs were used appropriately for severe lesions. As mentioned previously, to minimize bias, propensity score matching was used to adjust for known confounders of surgical risk. Nonetheless, this study must be interpreted in the context of some limitations. Although 598 patients were eligible to enter the matched comparison, only 132 pairs (or 264 
patients) were obtained (and peripheral vascular disease and reduced left ventricular ejection fraction could not be matched), suggesting a high degree of heterogeneity between the groups. Furthermore, although propensity score matching offers an opportunity to balance known and measurable confounders between study groups, there will always be differences in unknown confounders. In surgery, this is notably the surgeon's decision regarding treatment allocation. Still, this technique offers an opportunity to examine intermediate outcomes in an efficient and effective manner outside a randomized clinical trial setting. The generalizability of these results may be limited because this study was conducted from a single center of excellence.

The major limitation in this study was the sample size, particularly for the primary outcome of late survival. A sample size calculation was not included, and there remained few patients at risk after 7 years. For example, the Arterial Revascularization Trial, which showed no differences in survival between bilateral ITA grafting and single-ITA grafting in multiple arterial disease at 5 years, included a total sample of more than 3000 patients. ${ }^{9}$ The use of a composite end point of major adverse cardiovascular or cerebrovascular events, rather than all-cause mortality, would have increased the statistical power of the study.

Despite these limitations, Luthra and colleagues ${ }^{1}$ are to be commended for highlighting such an important issue in coronary surgery. American guidelines recommend that TAR may be reasonable for patients younger than 60 years with few comorbidities, whereas European guidelines recommend TAR for those with a reasonable life expectancy. ${ }^{10}$ The recommendations are class IIb and IIA, respectively, reflecting a paucity of high quality data on this topic. Since these guidelines were published, two meta-analyses have comprehensively examined the topic of multiarterial grafting. The meta-analysis by Gaudino and colleagues ${ }^{11}$ of 8 propensity score-matched studies included more than 10,000 patients and showed no difference in early mortality but a $20 \%$ reduction in late mortality among those receiving 3 arteries versus 2 arteries at mean 6-year follow-up. Similar results have been reported in a meta-analysis by Yanagawa and colleagues ${ }^{12}$ of randomized, controlled trials and observational studies including more than 130,000 patients comparing TAR with non-TAR grafting strategies. They also found no difference in short-term mortality and similarly saw a $15 \%$ reduction in late mortality, with study-reported median follow-up varying from 1 to 14 years. The most important caveat is that these conclusions regarding clinical outcomes are based on observational findings and not data from randomized trials. The findings from Luthra and colleagues ${ }^{1}$ reinforce these previous results that the inclusion of a third arterial graft poses no short-term harm and may have potential long-term benefit in carefully selected patients. Further, larger studies with long-term follow-up are required to determine whether 3 arteries are truly the trifecta needed to improve late survival.

\section{References}

1. Luthra S, Leiva-Juárez MM, Matuszewski M, Morgan IS, Billing JS. Does a third arterial conduit to the right coronary circulation improve survival? J Thorac Cardiovasc Surg. 2018;155:855-60.e1.

2. Taggart DP. Best practices in coronary revascularization procedures: are we where we should be? Curr Opin Cardiol. 2014;29:528-33.

3. Gaudino M, Tondi P, Benedetto U, Milazzo V, Flore R, Glieca F, et al. Radial artery as a coronary artery bypass conduit: 20-year results. J Am Coll Cardiol. 2016;68:603-10.

4. Tatoulis J, Buxton BF, Fuller JA. The Right Internal Thoracic Artery: The forgotten conduit-5,766 patients and 991 angiograms. The Annals of Thoracic Surgery. 2011;92:9-17.

5. Sabik JF IIIrd, Stockins A, Nowicki ER, Blackstone EH, Houghtaling PL, Lytle BW, et al. Does location of the second internal thoracic artery graft influence outcome of coronary artery bypass grafting? Circulation. 2008;118(14 Suppl):S210-5

6. Kurlansky PA, Traad EA, Dorman MJ, Galbut DL, Zucker M, Ebra G. Location of the second internal mammary artery graft does not influence outcome of coronary artery bypass grafting. Ann Thorac Surg. 2011;91:1378-83; discussion 1383-4.

7. Glineur D, D'hoore W, de Kerchove L, Noirhomme P, Price J, Hanet C, et al. Angiographic predictors of 3-year patency of bypass grafts implanted on the right coronary artery system: a prospective randomized comparison of gastroepiploic artery, saphenous vein, and right internal thoracic artery grafts. J Thorac Cardiovasc Surg. 2011;142:980-8.

8. Tatoulis J, Royse AG, Buxton BF, Fuller JA, Skillington PD, Goldblatt JC, et al. The radial artery in coronary surgery: a 5-year experience-clinical and angiographic results. Ann Thorac Surg. 2002;73:143-7; discussion 147-8.

9. Taggart DP, Altman DG, Gray AM, Lees B, Gerry S, Benedetto U, et al. Randomized trial of bilateral versus single internal-thoracic-artery grafts. $N$ Engl J Med. 2016;375:2540-9.

10. Kolh P, Kurlansky P, Cremer J, Lawton J, Siepe M, Fremes S. Transatlantic editorial: a comparison between European and North American guidelines on myocardial revascularization. J Thorac Cardiovasc Surg. 2016;152:304-16.

11. Gaudino M, Puskas JD, Di Franco A, Ohmes LB, Iannaccone M, Barbero U, et al. Three arterial grafts improve late survival: a meta-analysis of propensitymatched studies. Circulation. 2017;135:1036-44.

12. Yanagawa B, Verma S, Mazine A, Tam DY, Jüni P, Puskas JD, et al. Impact of total arterial revascularization on long term survival: a systematic review and meta-analysis of 130,305 patients. Int J Cardiol. 2017;233:29-36. 